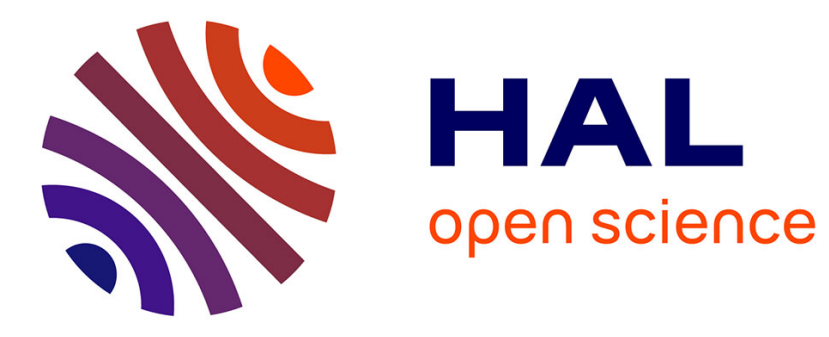

\title{
Sigma- and pi- electron structure of aza-azoles
}

Tadeusz M. Krygowski, Wojciech P. Oziminski, Christopher A. Ramsden

\section{To cite this version:}

Tadeusz M. Krygowski, Wojciech P. Oziminski, Christopher A. Ramsden. Sigma- and pi- electron structure of aza-azoles. Journal of Molecular Modeling, 2010, 17 (6), pp.1427-1433. 10.1007/s00894010-0844-z . hal-00624428

\section{HAL Id: hal-00624428 \\ https://hal.science/hal-00624428}

Submitted on 17 Sep 2011

HAL is a multi-disciplinary open access archive for the deposit and dissemination of scientific research documents, whether they are published or not. The documents may come from teaching and research institutions in France or abroad, or from public or private research centers.
L'archive ouverte pluridisciplinaire HAL, est destinée au dépôt et à la diffusion de documents scientifiques de niveau recherche, publiés ou non, émanant des établissements d'enseignement et de recherche français ou étrangers, des laboratoires publics ou privés. 


\title{
Sigma- and pi- electron structure of aza-azoles
}

Received: 21.06.2010 / Accepted: 31.08.2010

Tadeusz M. Krygowski ${ }^{1}$, Wojciech P. Oziminski ${ }^{2,3, 凶}$, and Christopher A. Ramsden ${ }^{4}$

${ }^{1}$ Department of Chemistry, University of Warsaw, Pasteura 1, 02093 Warsaw, Poland

${ }^{2}$ National Medicines Institute, Chełmska 30/34, 00725 Warsaw, Poland

${ }^{3}$ Institute of Nuclear Chemistry and Technology, Dorodna 16, 03195 Warsaw, Poland

${ }^{4}$ Lennard-Jones Laboratories, School of Physical and Geographical Sciences, Keele University, Keele, Staffordshire ST5 5BG, UK

*Email: wojozim@gmail.com; Tel. +48 228515230 ext.166; Fax: +48 228410652

\begin{abstract}
The reasons behind changes of aromaticity in 10 unsubstituted aza-azoles was analysed by employing the Natural Bond Orbital (NBO) approach at the MP2/6-311+G(d,p) level of theory. Sum of occupations of $p_{z}$ orbitals at atoms in the ring correlates well with the magnetism based aromaticity index NICS as well as with the number of nitrogen atoms in the ring. Changes of NICS depend strongly in a linear way on the number of NN bonds. Classification of azoles based on the number of pyridine-type nitrogen atoms vicinal to $\mathrm{NH}$ is supported by plotting the relative occupation of $\pi$ orbitals $\left(\pi_{\mathrm{occ}}\right)$ against the relative occupation of $\sigma$ orbitals $\left(\sigma_{\text {occ }}\right)$ for all individual atoms in rings.
\end{abstract}

Keywords Azoles $\cdot$ Aromaticity $\cdot \mathrm{HOMA} \cdot \mathrm{NICS} \cdot \mathrm{sEDA} \cdot \mathrm{pEDA} \cdot \mathrm{NBO}$ 


\section{Introduction}

Azoles belong to an interesting and important class of $\pi$-electron system $[1,2]$, which fulfill the Hückel $4 n+2$ rule but have different degrees of aromaticity [3]. In aza-azoles the aromatic stabilization energy (ASE) depends on the number and location of the pyridine-type nitrogen atoms in the ring, especially how many pyridine-type nitrogen atoms are next to the pyrroletype nitrogen atom [4]. The pyrrole-type nitrogen possesses an electron lone pair perpendicular to the molecular plane and nominally contributes two electrons to the aromatic sextet. There can also be up to four pyridine-type nitrogen atoms, each of them contributes a single electron to the electronic sextet from a $2 p_{z}$ orbital and their lone pairs lie in the ring plane. These two types of nitrogen atoms, and also the carbon atoms present in the ring, have their own $\sigma$-electron structure, which may in some way interfere with the $\pi$-electron structure, and contribute to the picture of $\pi$-electron delocalization. There is a long-standing dispute about how far $\pi$-electron delocalization or $\sigma$-electron structure is responsible for aromatic equalization of bonds length and other aromatic properties [5-10]. A number of approaches have shown either significant colinearities between some aromaticity indices or lack of correlation [11-13]. These contradictions may be due to different physical/chemical bases for the indices themselves or to specific relationships between $\sigma$ - and $\pi$ - electron contributions to the properties taken to measure "aromatic character". Hence, in this paper we investigate the interrelationship between the $\sigma$ - and $\pi$-electron structures in aza-azoles.

\section{Methods}

Geometry optimizations and all other calculations were performed at the MP2/6-311+G(d,p) level of theory using the Gaussian 03 suite of programs [14]. All optimizations were followed by frequency calculations to ensure that the calculated stationary points are true minima on the potential energy surface. Natural Bond Orbital (NBO) [15] analysis was performed by NBO 5.G program interfaced to Gaussian03 using MP2 density matrix with the keyword density=current. The NICS [16] aromaticity index was calculated as a shielding constant (taken with minus sign) of a ghost atom located at the geometric center of the ring and NICS(1) was calculated $1 \AA$ above the ring. 


\section{Results and discussion}

To analyze separately $\sigma$ - and $\pi$-electron distributions we employed an occupation partitioning scheme based on Natural Population Analysis (NPA). This partitioning scheme is based on NBO analysis, which is well known for producing reliable results for organic compounds, comparing to other charge partitioning methodologies like Mulliken population analysis which is strongly basis set dependent. The advantage of NPA approach lies also in the ease of separation of $\sigma$ - and $\pi$ - electronic systems in the case of flat aromatic molecules. If the molecule is oriented in the xy plane the $s, p_{x}$ and $p_{y}$ natural atomic orbitals (NAOs) occupations can be directly assigned to $\sigma$ - electronic system and the $p_{z}$ NAOs occupations to $\pi$ - electronic system. We used similar approach in our previous study about substituted benzene molecules [17].

In our approach the $\sigma$-electron population of the ring is calculated as a sum of the populations of the $s, p_{x}$ and $p_{y}$ natural atomic orbitals of the ring atoms. Subtracting the "nominal" number of $\sigma$ electrons expected for the studied system, expressed by variable "C" (see Eq. 1), gives the extent to which the studied system deviates from the "nominal" distribution: this value we call $s E D A$ [sigma Electron Donor-Acceptor]. The parameter "C" changes in the series of azoles because a pyrrole-type nitrogen atom contributes only three electrons to the $\sigma$-system (like carbon) but each pyridine-type nitrogen atom contributes four electrons to the $\sigma$-system. Thus, the value of "C" is equal to 15 in the case of pyrrole $\mathbf{1}$ but is incremented as the number of pyridine-type atoms increases, reaching the maximum value of 19 for pentazole $\mathbf{1 0 .}$

Similarly, the $p E D A$ [pi Electron Donor-Acceptor] parameter is obtained by summing up the populations of the $p_{z}$ natural atomic orbitals (perpendicular to the molecule plane) and subtracting the "nominal" value of 6 (two electrons from pyrrole-type nitrogen atoms and one electron from each other atom). Thus, $p E D A$ [Eq. 2] expresses the deviation from the "nominal" or "ideal" value of the electronic sextet.

$$
\begin{aligned}
& s E D A=\sum_{j=1}^{5} \sigma^{j}-C \\
& p E D A=\sum_{j=1}^{5} \pi^{j}-6
\end{aligned}
$$


An analysis of $p E D A$ shows how the distribution of $\pi$ electrons depends on the number of nitrogen atoms in the ring. Fig. 1 presents this relationship for which the correlation coefficient (CC) is 0.993 . This means that an increase of the number of electronegative nitrogen atoms, which replace less electronegative $\mathrm{CH}$ units, increases the population of $\pi$ electrons in the ring. This necessarily means that the $\sigma$ - electron structure of the ring is less populated.

$<$ Figure 1>

Azoles may be classified [4] according to the number $\left(\mathrm{N}_{2,5}\right)$ of pyridine-type nitrogen atoms neighboring the $\mathrm{NH}$ group in the ring. Thus, the " $\mathrm{N}_{2,5}=0$ " group are pyrrole $\mathbf{1}, 1 H$-imidazole $\mathbf{3}$ and $4 H-1,2,4$-triazole 7, the " $\mathrm{N}_{2,5}=1$ " group are $1 H$-pyrazole $2,1 H$-1,2,3-triazole 4, $1 H$-1,2,4triazole $\mathbf{6}$ and $1 H$-tetrazole $\mathbf{8}$, and the ' $\mathrm{N}_{2,5}=2$ " group are $2 \mathrm{H}$-1,2,3-triazole 5, $2 \mathrm{H}$-1,2,3tetrazole 9 and pentazole 10. When $p E D A$ values are plotted against $s E D A$ values for all ten azoles (Scheme 1), the observed correlation is expected since the $\pi$-structure may only take electrons from the $\sigma$-structure. Fig. 2 presents this dependence $(\mathrm{CC}=-0.987)$.

$<$ Scheme 1>

$<$ Figure 2>

It should be noted that changes in $p E D A$ are dramatically smaller than those for $s E D A$. When the $\mathrm{CH}$ units are replaced by pyridine nitrogen atoms the total $\pi$-population of the ring increases and the $\sigma$-population decreases. The decrease of $\sigma$-population is partially because hydrogen atoms are source of electron density for $\sigma$-system and the number of hydrogen atoms becomes smaller and smaller when consecutive $\mathrm{CH}$ groups are replaced by $\mathrm{N}$ atoms.

Deeper analysis of the above relationship (Fig. 2) is achieved by plotting the relative occupation of $\pi$ orbitals $\left(\pi_{\text {occ }}\right)$ against the relative occupation of $\sigma$ orbitals $\left(\sigma_{\text {occ }}\right)$ for individual atoms. In this way are obtained three scatter plots: two for the two types of nitrogen atom (Figs. 3 and 4) and one for the carbon atoms (Fig. 5).

$<$ Figure 3>

$<$ Figure 4>

$<$ Figure 5> 
When all the points are taken into account, lack of a good correlation in the scatter plots in Figs. 3, 4 and 5 is not unexpected. Atoms participating in the ring differ in their electronegativities (pyrrole-type, pyridine-type and carbon) and also in their close environment. Nevertheless, a general trend is common to all three relationships: the slopes are positive indicating the necessity that if the $\sigma$ structure becomes richer in electrons then the $\pi$ structure must lose them. However in all three cases (Fig. 3-5) three well-separated clusters (or subsets) can be observed for which the slopes are negative. The plots show that the changes in $\sigma / \pi$ relationships depend on the electronegativity of atoms involved in the whole structure of azoles, as well as their neighborhood. Moreover, the clusters are grouped following the rule dependent on the number of 2,5 pyridine-type nitrogen atoms neighboring the relevant atom.

For the dependence of orbital occupations of pyrrole-type nitrogen N1 $\pi_{\mathrm{occ}}$ on N1$\sigma_{\mathrm{occ}}$, (Fig. 3 ), the type " $\mathrm{N}_{2,5}=2$ " systems lose more $\pi$ electrons than those of type " $\mathrm{N}_{2,5}=1$ " and these still less than for type " $\mathrm{N}_{2,5}=0$ ". This rule is nicely illustrated by showing the occupation on these atoms in the four simplest cases: for pyrrole 1, imidazole $\mathbf{3}$, pyrazole $\mathbf{2}$ and 2H-1,2,3-triazole 5, as shown in Scheme 2.

\section{$<$ Scheme 2>}

The highest occupation on the pyrrole-type nitrogen occurs in pyrrole 1, where there are no interactions with any nitrogen atoms, then for imidazole $\mathbf{3}$, where the pyridine-type nitrogen atom is distant. For the examples of neighboring one " $\mathrm{N}_{2,5}=1$ " and two " $\mathrm{N}_{2,5}=2$ " pyridine-type nitrogen atoms ( 3 and $\mathbf{5}$ ), the occupation on the pyrrole-type nitrogen atom decreases significantly. Thus, it may be concluded that direct interactions between pyridine-type nitrogen and pyrrole-type nitrogen atoms is the most effective factor for delocalization of $p_{z}$ electrons from pyrrole nitrogens towards the vicinal nitrogen atoms and then further in the ring. This observation can be rationalized as follows: electronegative nitrogen atoms replacing $\mathrm{CH}$ cause a decrease of $\pi$ electron occupation on the $p_{z}$ orbital of the pyrrole-type nitrogen atom relative to the effect due to less electronegative carbon atoms. The electron pair of this nitrogen atom is drawn out to the ring as the number of electronegative pyridine nitrogen atoms increase, replacing less electronegative carbon atoms. The $\sigma$ system of the ring may withdraw electrons also from $\mathrm{C}-\mathrm{H}$ bonds by means of an inductive effect. As the consecutive pyridine-like nitrogen atoms are introduced into the ring the number of $\mathrm{C}-\mathrm{H}$ bonds is decreasing so the possibility to draw $\sigma$ electrons into the ring is also decreased. 
For the dependence of pyridine-type nitrogen $\mathrm{N} \pi_{\mathrm{occ}}$ on $\mathrm{N} \sigma_{\mathrm{occ}}$, (Fig. 4) a similar trend is observed. Again, three classes of pyridine nitrogen form clusters, according to the number of nitrogen atoms directly bonded to the relevant nitrogen atom, and the slopes are again negative. In each cluster, the more nitrogen atoms, then the lower is $\pi_{\text {occ }}$. Similarly, for the dependence of carbon atoms $\mathrm{C} \pi_{\mathrm{occ}}$ on $\mathrm{C} \sigma_{\mathrm{occ}}$, (Fig. 5), the slopes in clusters are also negative and the occupation of the $\pi$-orbital on a carbon atom increases with a decrease of the number of nitrogen atoms.

We conclude that two factors, which are not always independent, play an important role in deciding the relationship between $\sigma$ - and $\pi$-electron structure in azoles. The first factor is the number of pyridine-type nitrogen atoms $\left(\mathrm{N}_{2,5}=0,1\right.$ or 2$)$ neighboring the pyrrole nitrogen $(\mathrm{NH})$, and the second is the number of $\mathrm{CH}$ units replaced by pyridine-type nitrogen atoms.

One more interesting symptom of the dependence of $\pi$-electron structure on the relative locations of pyridine-and pyrrole-type nitrogen atoms is that mean HOMA values for the subgroups [4] " $\mathrm{N}_{2,5}=0$ ", " $\mathrm{N}_{2,5}=1$ " and " $\mathrm{N}_{2,5}=2$ " increase as $\mathrm{N}$ increases, as shown in Schemes 3. Similarly, mean ASE values (taken from [3]) distinguish between these three subgroups.

\section{$<$ Scheme 3>}

The population of electrons located on $\pi$ orbitals in the ring ( $p E D A)$ is nicely related to the aromaticity index NICS(1) [18] indicating that $p E D A$ may also act as a quantitative measure of azole aromaticity. Since the population of $\pi$-electrons depends on their delocalization from the pyrrole-type nitrogen atom, the less $\pi$-electrons are present on this atom, the more they are delocalized on the ring and the more aromatic is the ring as measured by delocalization indices such as NICS(1). The correlations in Figs. 6 and 7 support this view. The greater value of $p E D A$, i.e. the population of $\pi$-molecular orbitals, the more negative NICS(1), i.e. the more aromatic the system in question. The same type of dependence is present for NICS(1) or NICS(1) ZZ . When NICS(1) values are plotted against the number of NN bonds, a linear relationship is significant, as shown in Figure 8.

\section{$<$ Figure 6>}

<Figure 7>

<Figure 8> 
The data from Scheme 3 show one more interesting feature. The averaged ASE and HOMA values for azole subgroups $\mathrm{N}_{2,5}=0, \mathrm{~N}_{2,5}=1$, and $\mathrm{N}_{2,5}=2$ increase with an increase of the number of possible interactions between the $\mathrm{NH}$ group and a lone pair of a pyridine-type nitrogen atom. These interactions are associated with the change of HNN angles in molecules that are unsymmetrical and the values are smaller than those observed for HNC angles. The averaged value for three cases with one-sided (lone pair)/ $\mathrm{NH}$ interactions [1H-pyrazole 2, $1 H$-1,2,3triazole 4 and $1 H$-124-triazole 6] is $119.1^{\circ}$ whereas for (lone pair)/CH interactions [pyrrole $\mathbf{1}$, imidazole 3 and $4 H-1,2,4$-triazole 7] the averaged value is $126.2^{\circ}$. Evidently, the attraction between lone pair and NH-bond decreases the angle. Moreover, as results from Scheme 3 indicate, the number of such interactions is also associated with an increase of aromaticity, i.e. the ASE and HOMA values. It is also interesting to note that natural charges on pyrrole-type nitrogen atoms are for $\mathrm{N}_{2,5}=0, \mathrm{~N}_{2,5}=1$ and $\mathrm{N}_{2,5}=2$ type atoms $\sim 0.53 \mathrm{e}, \sim 0.33 \mathrm{e}$ and $\sim 0.13 \mathrm{e}$, respectively, indicating that pyridine/pyrrole $\mathrm{NH}$ interactions decrease charge on the $\mathrm{NH}$ nitrogen atom.

An increase of ASE on a sequence of systems belonging to subgroups $N_{2,5}=0,1$ and 2 is nicely associated with the change of structure, i.e. the value of angle $\mathrm{XNH}-\alpha$. For subclass " $\mathrm{N}_{2,5}=0$ " $\alpha=124.9$. for subclass " $\mathrm{N}_{2,5}=1$ ", where the interaction is one sided $\alpha=118.6$, and for symmetric class " $\mathrm{N}_{2,5}=2$ " $\alpha=121.2$. A reasonable explanation is that interaction of lone pair with $\mathrm{N}-\mathrm{H}$ dipole (Fig. 9B) is attractive, and thus may be stabilizing the system in question.

$<$ Figure 9>

\section{Conclusions}

Occupation of molecular $\pi$ orbitals in azoles depends linearly on the number of nitrogen atoms: the more nitrogen atoms then the higher occupation.

Classification of aza-azoles by counting $\mathrm{NH} / \mathrm{N}$ - lone pair interactions $\left(\mathrm{N}_{2,5}\right)$ is documented by dependences of $p E D A$ on $S E D A$ estimated for pyridine-like nitrogen, pyrrole-like nitrogen and carbon atoms. The three classes of azoles $\left(\mathrm{N}_{2,5}=0,1\right.$ or 2$)$ clearly differ when aromatic stabilization energies (ASE) or HOMA values are compared. 
Aromaticity of azoles follows an additivity rule: NICS(1) correlates linearly with the number of NN bonds as well as with the number of nitrogen atoms.

Interactions between $\mathrm{NH}$ bond and the lone pair of the neighboring pyridine-type nitrogen atom lead to a dramatic decrease of $\mathrm{CNH}$ angle: $118.6^{\circ}$ for pyrazole compared to $124.9^{\circ}$ for pyrrole.

\section{Acknowledgments}

Computational Grant G31-10 from the Interdisciplinary Centre of Mathematical and Computer Modelling (ICM) at Warsaw University is gratefully acknowledged. 


\section{References}

1. Katritzky AR, Ramsden CA, Joule JA, Zhdankin VV (2010) Handbook of Heterocyclic Chemistry, $3^{\text {rd }}$ Edn, Pergamon

2. Katritzky AR, Ramsden CA, Scriven EFV, Taylor RJK (2008) Comprehensive Heterocyclic Chemistry - III', Vols 3-6, Elsevier, Oxford

3. Cyrański MK, Krygowski TM, Katritzky AR, Schleyer PvR (2002) J Org Chem 67:13331338

4. Ramsden CA (2010) Tetrahedron 66:2695-2699

5. Shaik SS, Hiberty PC, Ohanessian G, Lefour JM (1985) Nouv J Chim 9:385-388

6. Shaik SS, Hiberty PC, Ohanessian G, Lefour JM (1985) J Org Chem 50:4657-4659

7. Hiberty PC, Shaik SS, Lefour JM, Ohanessian GJ (1988) J Phys Chem 92: 5086-5094

8. Jug K, Köster AM (1990) J Am Chem Soc 112: 6772-6777

9. Shaik SS, Shurki A, Danovich D, Hiberty PC (2001) Chem Rev 101:1501-1540

10. Jug K, Hiberty PC, Shaik S (2001) Chem Rev 101:1477-1500

11. Katritzky AR, Barczyński B, Musumurra G, Pisano D, Szafran M (1989) J Am Chem Soc 111:7-15

12. Krygowski TM, Ciesielski A, Bird CW, Kotschy A (1995) J Chem Inf Comput Sci 35:203-210

13. Katritzky AR, Karelson M, Sild S, Krygowski TM, Jug K (1998) J Org Chem 63: 52285231

14. Gaussian 03, Rev E.01 (2001) Gaussian Inc, Wallingford CT

15. Reed AE, Curtiss LA, Weinhold F (1988) Chem Rev 88:899-926

16. Schleyer PvR, Maerker C, Dransfeld A, Jiao H, Hommes NJRvE (1996) J Am Chem Soc 118:6317-6318

17. Oziminski WP, Dobrowolski JC (2009) J Phys Org Chem 22:769-778

18. Chen Zh, Wannere CS, Corminboef C, Puchta R, Schleyer PvR (2005) Chem Rev 105:3842-3888. 


\section{Figure captions}

Scheme 1 Pyrrole and the aza-azoles

Scheme 2 Total occupations of nitrogen $p_{z}$ natural atomic orbitals of selected azoles

Scheme 3 Azoles showing HOMA and ASE (italic) values together with HOMA mean and $\mathrm{ASE}_{\text {mean }}$ for each sub-group

Fig. 1 The linear relationship between $p E D A$ and the number of nitrogen atoms in azoles. Regression equation: $\mathrm{y}=0.0076 \mathrm{x}-0.1083 ; \mathrm{CC}=0.993$

Fig. 2 The inter-relationship of total-ring $p E D A$ on $s E D A$. Regression equation: $\mathrm{y}=-$ $0.0329 \mathrm{x}-0.0666 ; \mathrm{CC}=0.987$

Fig. 3 The inter-relationship of pyrrole-type nitrogen $\pi_{\mathrm{occ}}$ on $\sigma_{\mathrm{occ}}$ (left: $\mathrm{y}=-0.7399 \mathrm{x}-$ $0.0988 ; \mathrm{CC}=0.995)($ middle: $\mathrm{y}=-0.5743 \mathrm{x}-0.0625 ; \mathrm{CC}=0.811)($ right: $\mathrm{y}=-$ $0.1772 \mathrm{x}-0.2904 ; \mathrm{CC}=0.851$ )

Fig. 4 The inter-relationship of pyridine-type nitrogen $\pi_{\mathrm{occ}}$ on $\sigma_{\mathrm{occ}}$ (left: $\mathrm{y}=-1.0181 \mathrm{x}$ 0.0069; $\mathrm{CC}=0.969)($ middle: $\mathrm{y}=-0.9391 \mathrm{x}+0.204 ; \mathrm{CC}=0.892)($ right: $\mathrm{y}=-$ $0.5152 \mathrm{x}+0.3138 ; \mathrm{CC}=1)$

Fig. 5 The inter-relationship for carbon atoms: $\pi_{\text {occ }}$ on $\sigma_{\text {occ }}($ left: $y=-0.4967 x-0.113$; CC $=0.986)($ middle: $\mathrm{y}=-0.7975 \mathrm{x}+0.0223 ; \mathrm{CC}=0.881)($ right: $\mathrm{y}=-0.2058 \mathrm{x}+0.1168$; $\mathrm{CC}=1)$

Fig. 6 The inter-relationship of NICS(1) on $p E D A$. Regression equation: $\mathrm{y}=-173.85 \mathrm{x}-$ $27.466 ; \mathrm{CC}=0.9583$ 
Fig. 7 Dependence of NICS(1) $)_{z Z}$ on lone-pair orbital occupation. Regression equation: $\mathrm{y}=$ $74.71 \mathrm{x}-147.73 ; \mathrm{CC}=-0.9745$

Fig. 8 The inter-relationship of NICS(1) on the number of NN bonds. Regression equation: $\mathrm{y}=-1.0294 \mathrm{x}-10.765 ; \mathrm{CC}=0.9922$

Fig. 9 Angles $\mathrm{XNH}(\mathrm{X}=\mathrm{C}$ or $\mathrm{N})$ for molecule of class "0" (A), of class "1" (B) and of class "2" (C) 
<smiles>c1cc[nH]c1</smiles>

$1 \mathrm{H}$-pyrrole

1<smiles>C=CNC=S</smiles>

$1 H-1,2,3$-triazole 4<smiles>Sc1cnnnn1</smiles>

$1 \mathrm{H}$-tetrazole

8

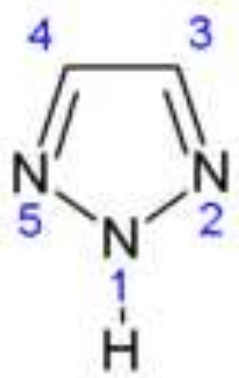

2H-1,2,3-triazole 5<smiles></smiles>

2H-tetrazole 9<smiles>c1cn[nH]c1</smiles><smiles>c1c[nH]cn1</smiles>

$1 \mathrm{H}$-pyrazole $1 \mathrm{H}$-imidazole 2<smiles></smiles>

1H-1,2,4-triazole 6<smiles>c1nnc[nH]1</smiles>

4H-1,2,4-triazole 7<smiles></smiles>

$1 \mathrm{H}$-pentazole 


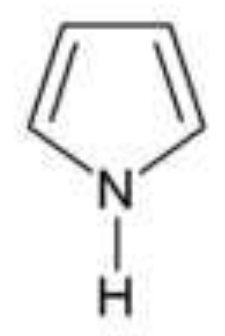

1.550

$1 \mathrm{H}$-pyrrole

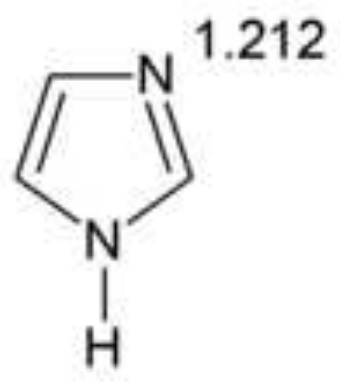

1.542

$1 \mathrm{H}$-imidazole

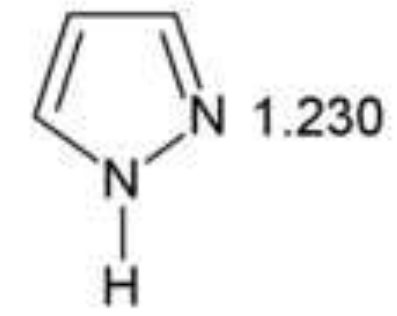

1.513

$1 H$-pyrazole
1.203

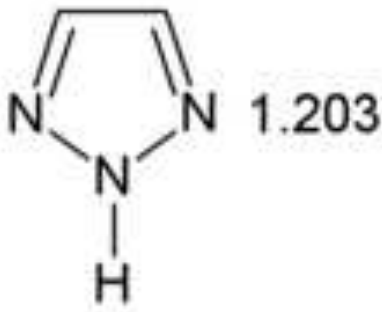

1.466

$2 H-1,2,3-$ triazole 
Sub-group " $\mathrm{N}_{2,5}=0$ " HOMA $_{\text {mean }}=0.870, \mathrm{ASE}_{\text {mean }}=18.1$

$0.876(20.57) \quad 0.908(18.78) \quad 0.827(14.96)$
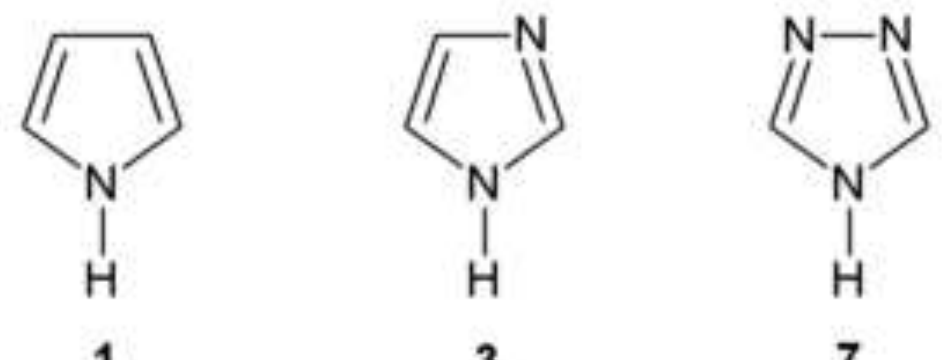

1

3

7

Sub-group " $\mathrm{N}_{2,5}=1 "$ HOMA $\mathrm{H}_{\text {mean }}=0.924, \mathrm{ASE}_{\text {mean }}=21.9$

$0.926(23.70) \quad 0.938(21.33) \quad 0.931(24.37) \quad 0.900(18.26)$
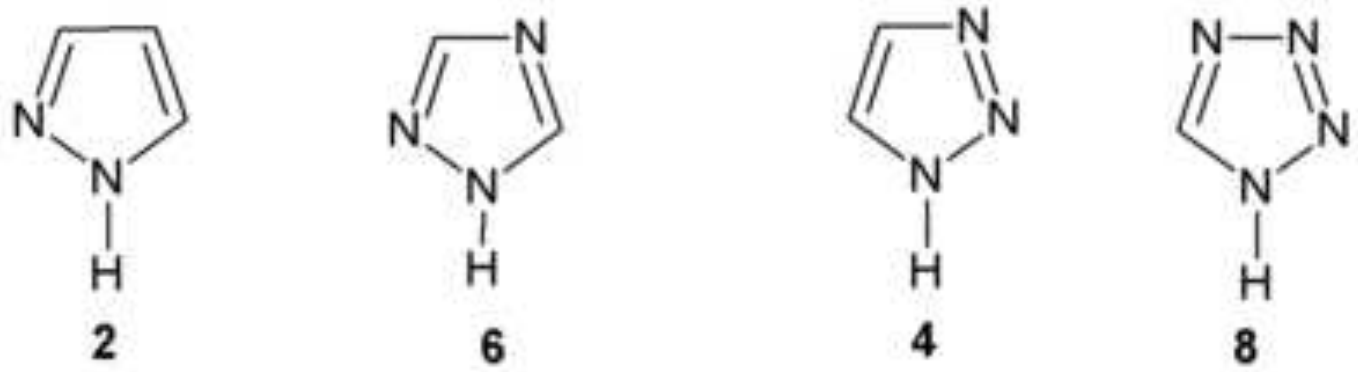

Sub-group " $\mathrm{N}_{2,5}=2$ " HOMA $_{\text {mean }}=0.944, \mathrm{ASE}_{\text {mean }}=26.6$



5
$0.924(26.49)$<smiles>c1nnn[nH]1</smiles>

9
0.948<smiles>c1nnn[nH]1</smiles>

10 


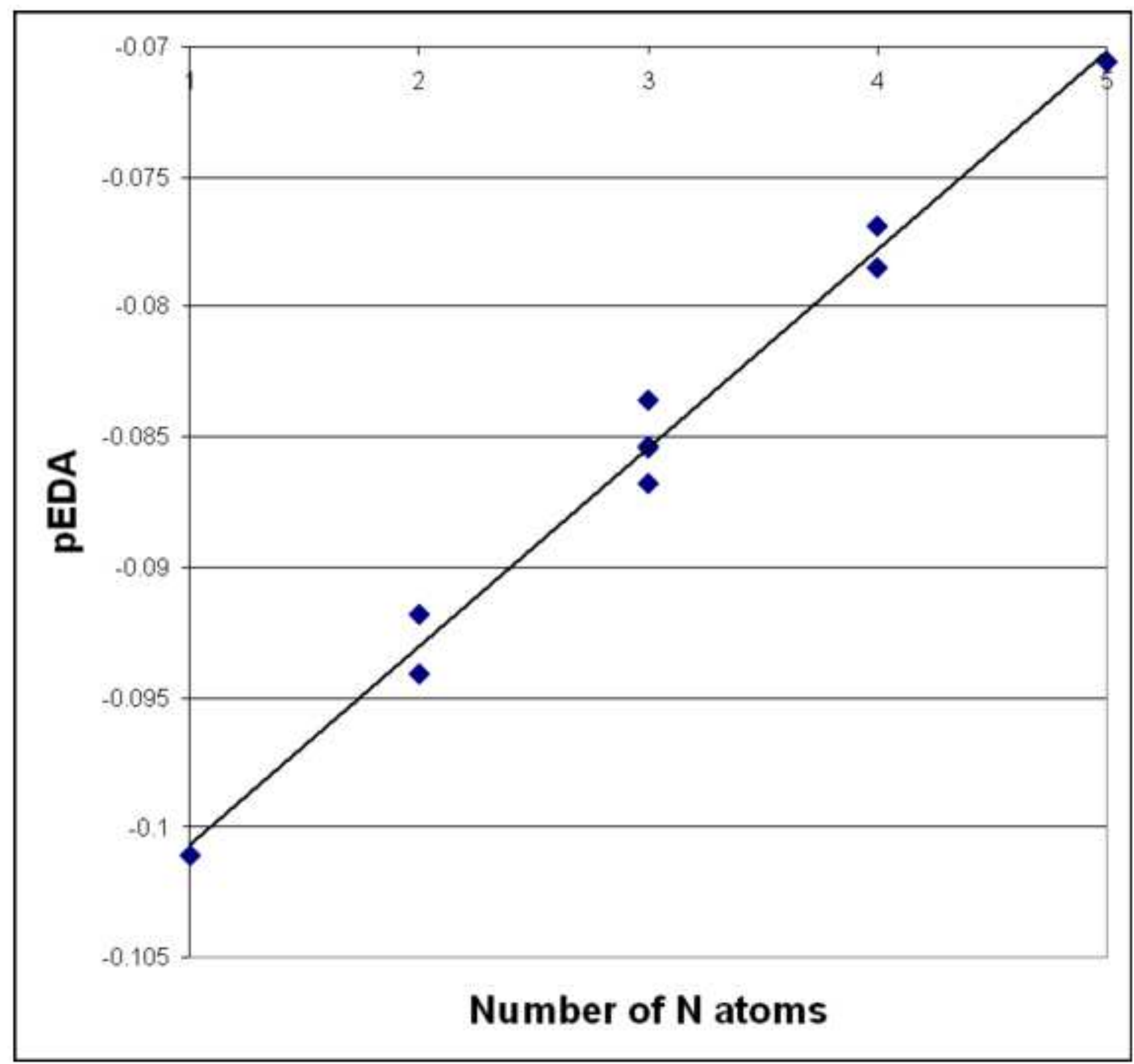




\section{Figure 2}

Click here to download high resolution image

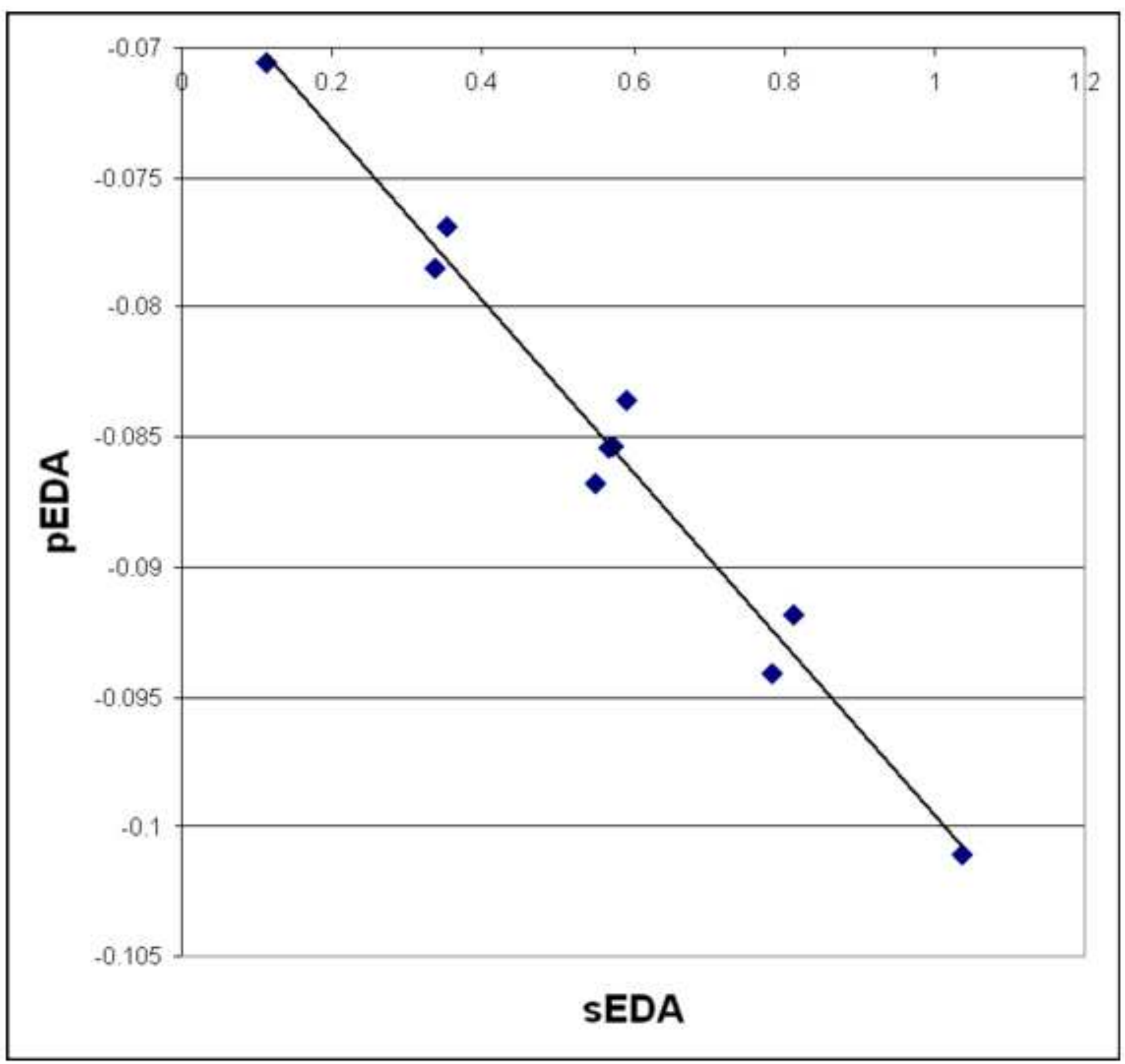




\section{Figure 3}

Click here to download high resolution image

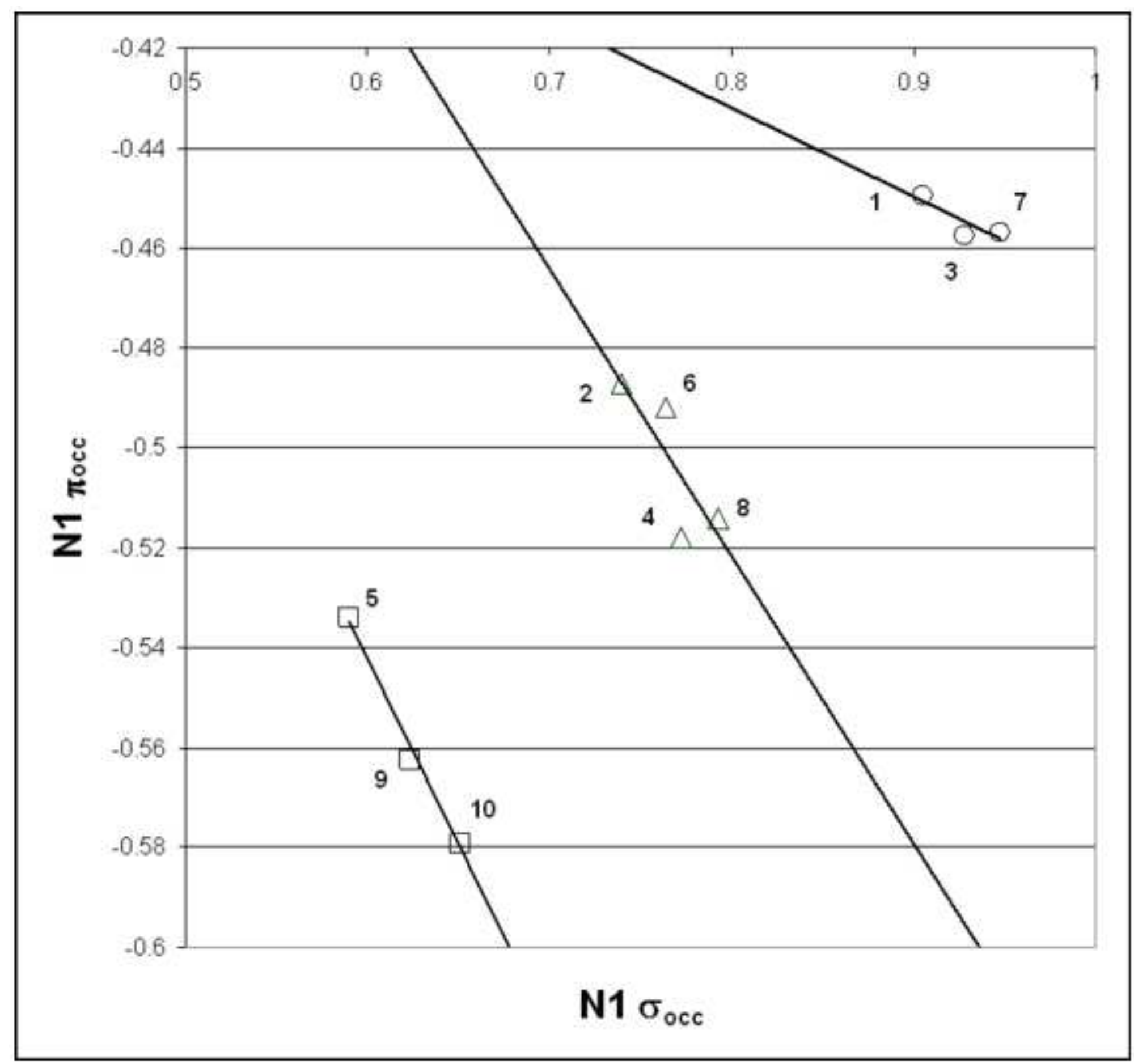









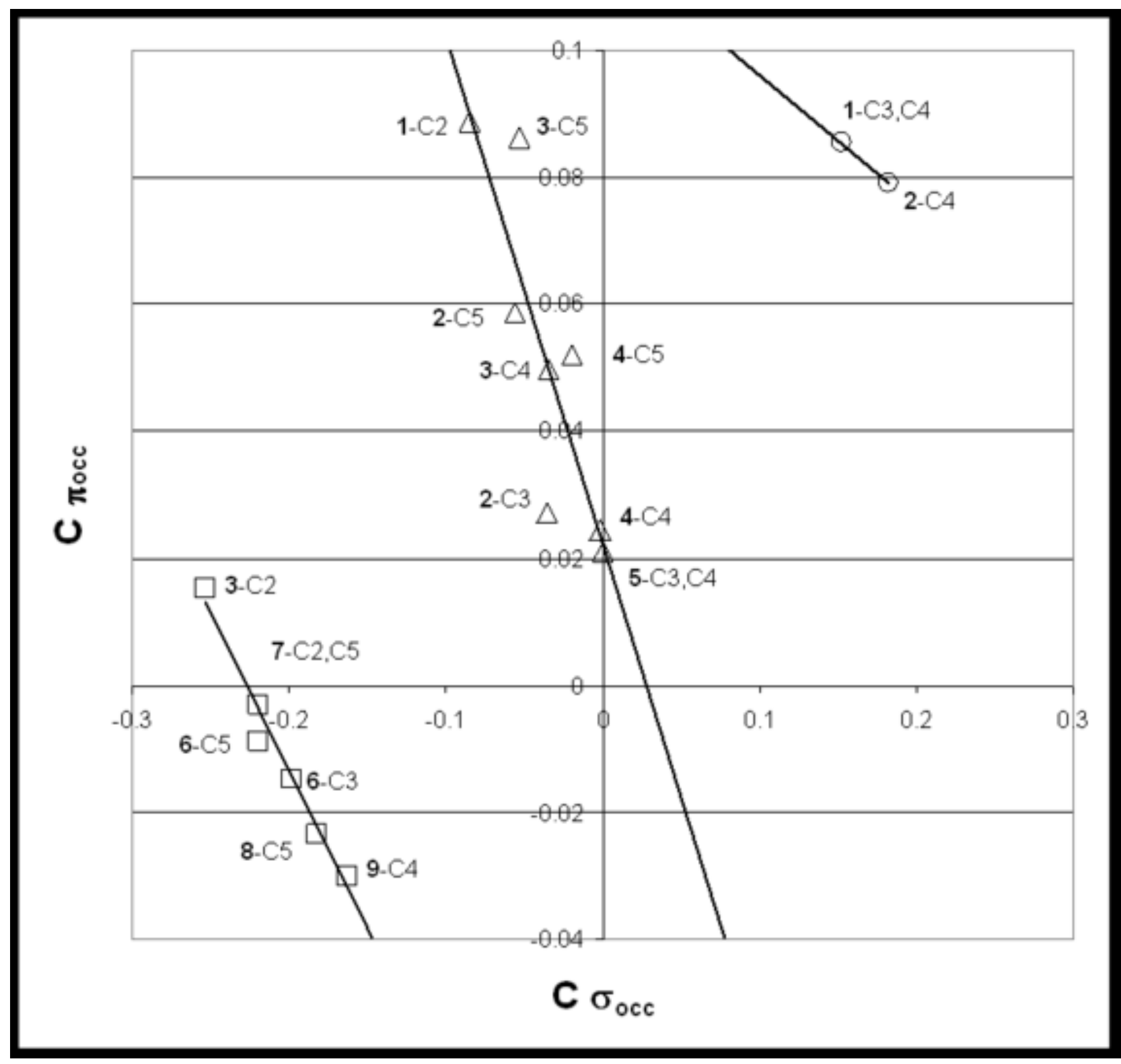


Click here to download high resolution image

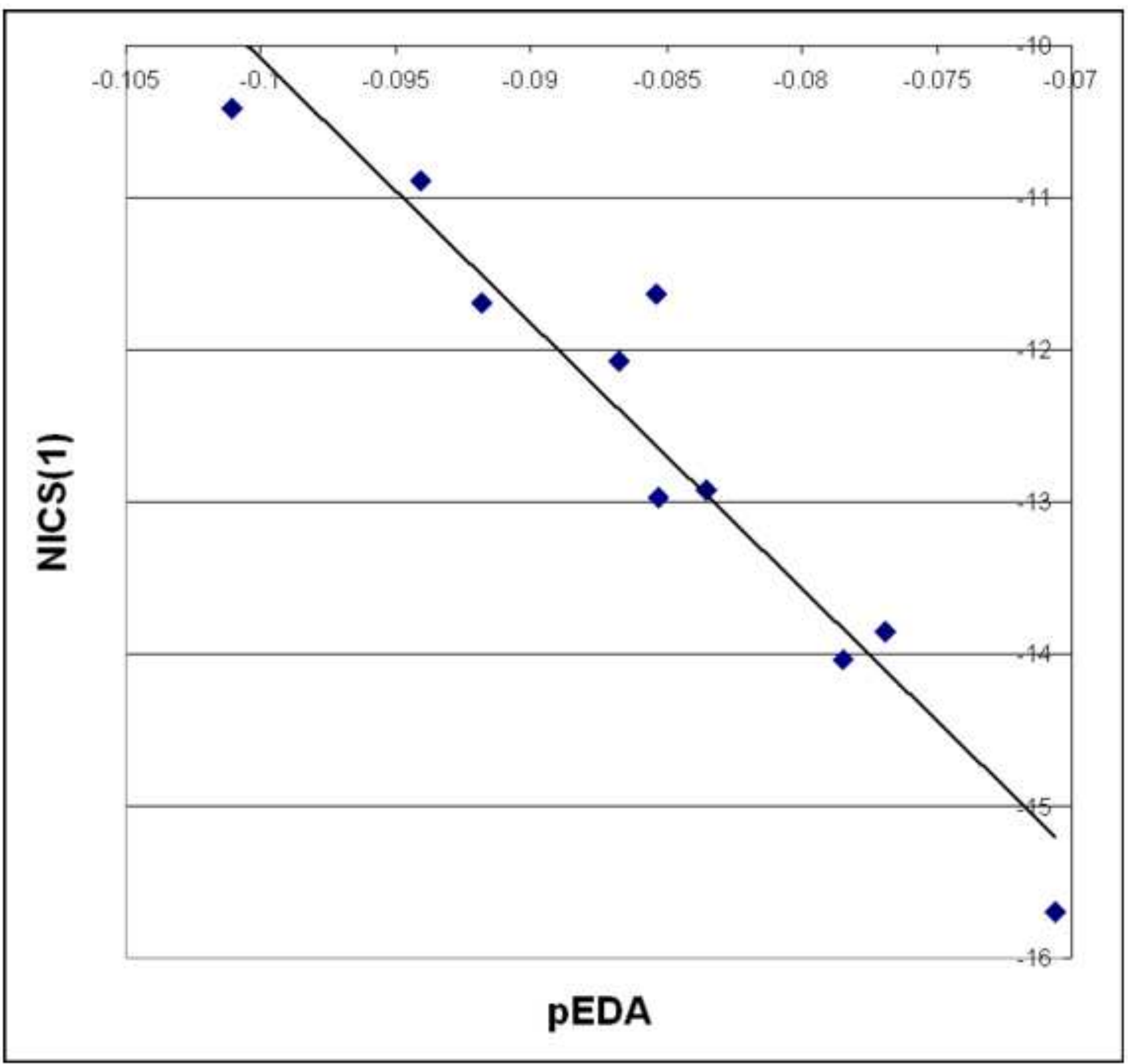




\section{Figure 7}

Click here to download high resolution image






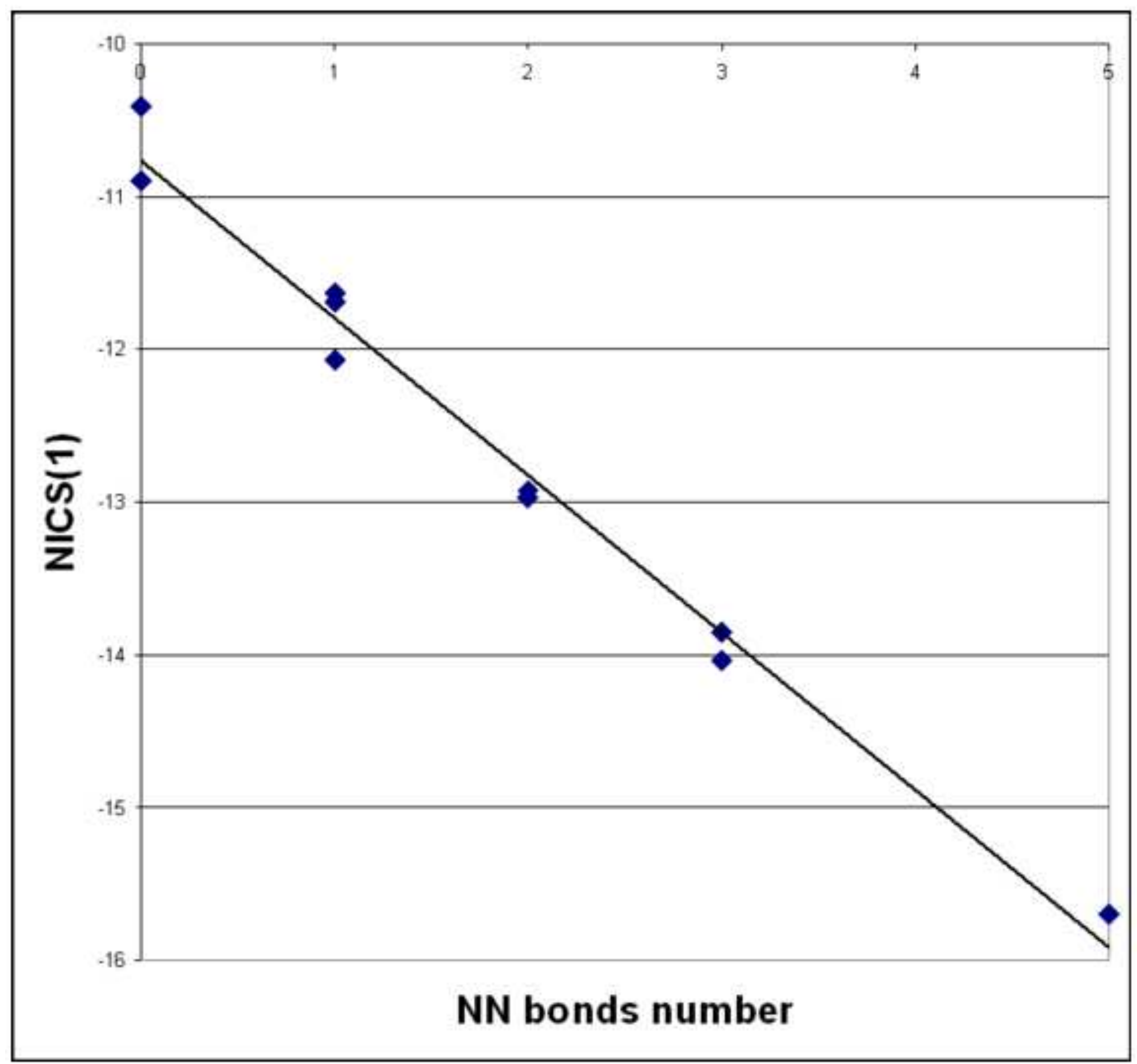


Click here to download high resolution image

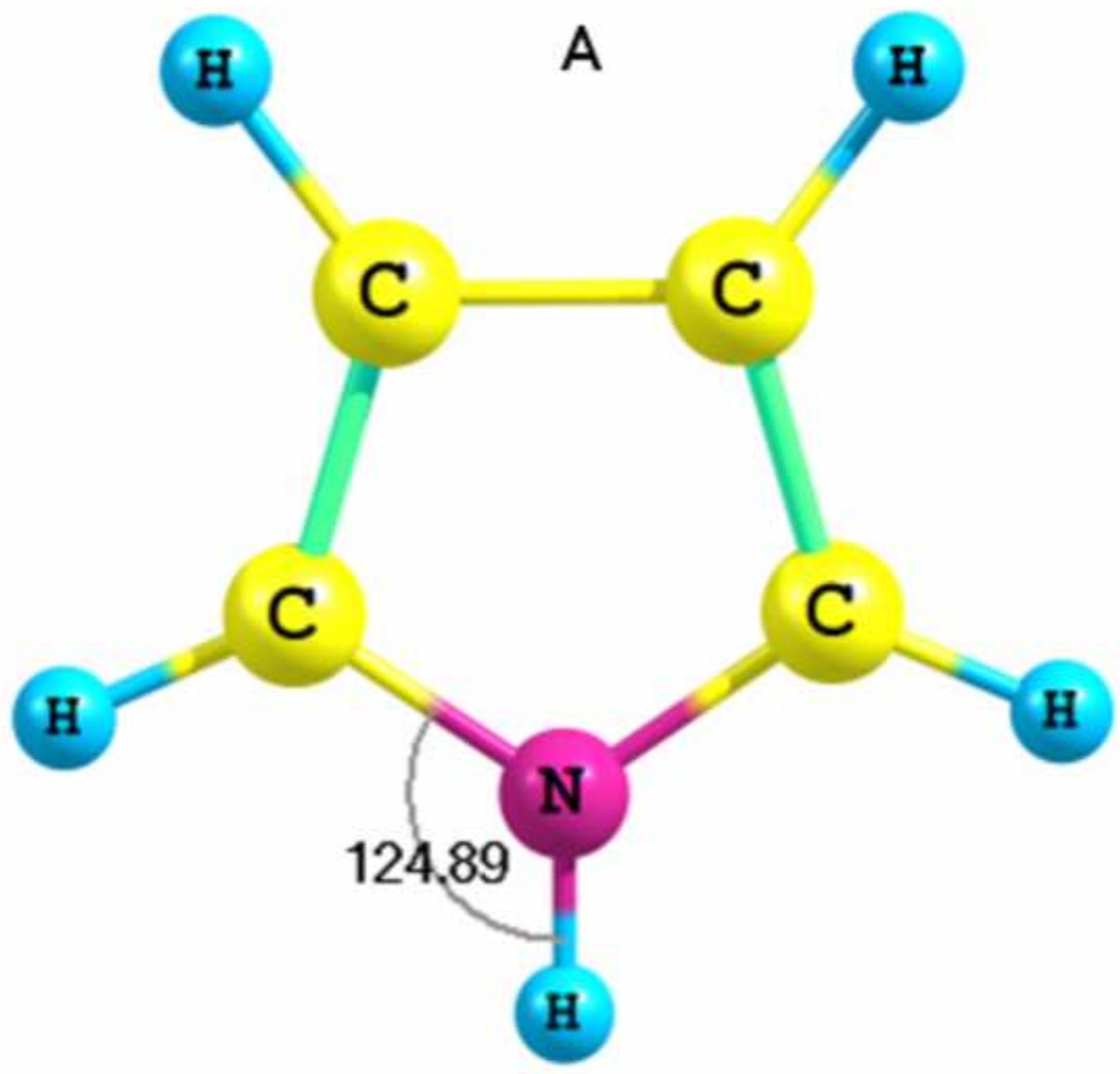


Figure $9 \mathrm{~b}$
Click here to download high resolution image




Figure $9 c$
Click here to download high resolution image

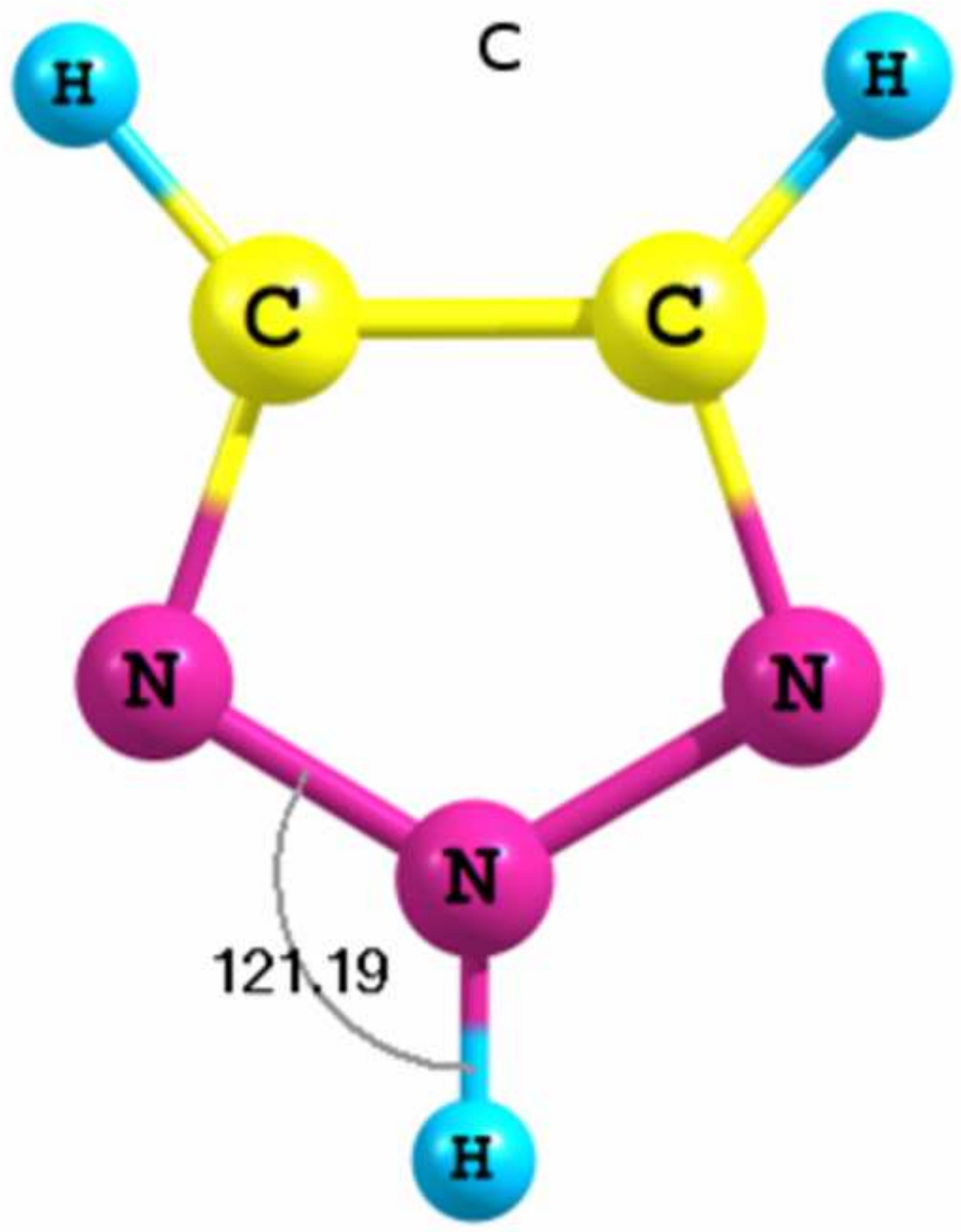

